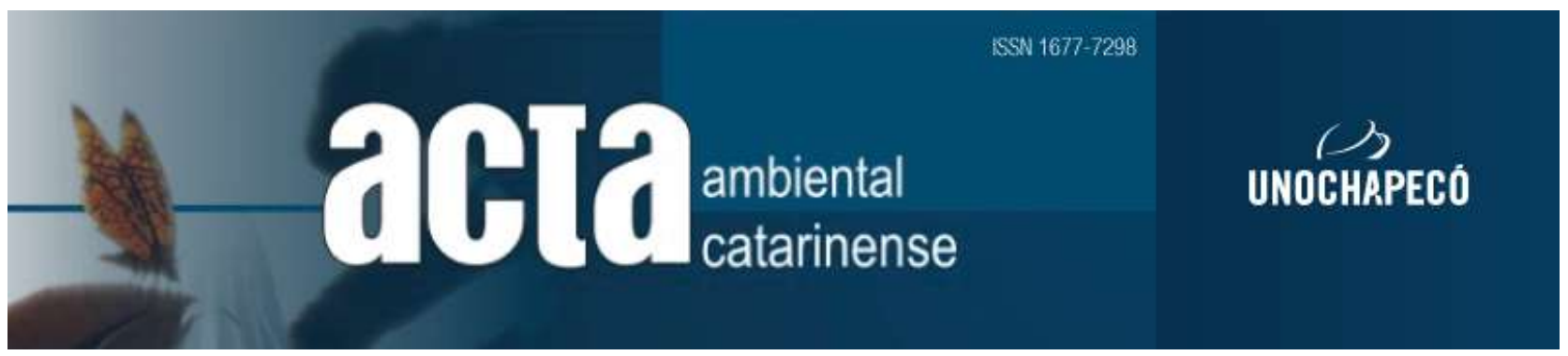

\title{
Anurofauna Terrestre da Floresta Estadual de SANTANa
}

\author{
Eduardo Biella ${ }^{1}$ \\ Huilquer Francisco Vogel ${ }^{2}$
}

Resumo

Dentre os vertebrados, os anfíbios são os que apresentam maior declínio em riqueza e abundância. Estudos sobre a diversidade de anfíbios são de extrema importância, pois fornecem subsídios para pesquisas em diversas áreas da biologia, que são fundamentais para a determinação de áreas prioritárias para a conservação. Assim, este trabalho teve por objetivo a descrição da estrutura da anurofauna da Floresta Estadual de Santana, Sudeste do Paraná. As amostragens ocorreram em um remanescente de Floresta Ombrófila Mista, com 60, 50ha, localizada no município de Paulo Frontin. As amostragens ocorreram de novembro 2018 a fevereiro de 2019 por meio de seis armadilhas de interceptação e queda (pitfall-trap), com volume de 200 litros e profundidade de $85 \mathrm{~cm}$, totalizando 33 amostragens de dois dias cada, cerca de nove por mês. Registrou-se uma riqueza de 13 espécies, onde as famílias Hylidae e Leptodactylidae foram as mais representativas, resultado comum em estudos realizados em regiões neotropicais. Tais dados possuem como implicações o preenchimento de uma lacuna espacial amostral e a obtenção de uma lista de espécies, informações úteis para a elaboração do plano de manejo da Unidade de Conservação.

Palavras-chave: Mata Atlântica, Floresta Ombrófila Mista, Anfíbios.

\section{TERRESTRIAl ANURAnS From the SANTANA' Statal Forest}

\begin{abstract}
Among vertebrates, amphibians show the greatest decline in richness and abundance. Studies about amphibians' diversity are extremely important to provide subsidies for research in several areas of biology, fundamental for determining priority areas for conservation. Thus this work aimed to describe the anurofauna of the Santana State Forest. The sampling was performed in a remnant of Mixed Ombrophilous Forest, with 60, 50ha, located in the municipality of Paulo Frontin, Paraná.

1 Discente na Universidade Estadual do Paraná (UNESPAR) Campus União da Vitória - PR. E-mail: eduardobiella@live.com

2 Docente na Universidade Estadual do Paraná (UNESPAR) Campus União da Vitória-PR. E-mail: huilquer@unespar.edu.br
\end{abstract}


The samplings took place from november 2018 to february 2019 through 6 pitfall-trap, with a size of 200 liters and $85 \mathrm{~cm}$ of deep, totaling 33 samples with two days each, nine per month. The counted richness was 13 species and the families Hylidae and Leptodactylidae were the most representative. This result being common in a study carried out in Neotropical regions. Such data have as implications the filling of a spatial sample gap and obtaining a list of species, useful information for the preparation of the management plan of the Conservation Unit.

Keywords: Atlantic Forest, Mixed Ombrophilous Forest, Amphibians.

\section{INTRODUÇão}

A Mata Atlântica (doravante MA) é considerada a segunda maior floresta pluvial tropical das Américas, caracterizada por conter fitofisionomias de florestas ombrófilas, estacionais, restingas, campos, manguezais entre outas (ATLAS, 2017, p.7; MINISTÉRIO, 2020). Dentre estas, a Floresta Ombrófila Mista (FOM) estende-se por grande parte da região Sul do Brasil. Ela esta sendo devastada ao longo dos últimos dois séculos, principalmente pelo corte de espécies arbóreas e de interesse econômico, como a araucária e a imbuia, além da prática da agricultura em grande escala (NODARI, 2009; MONTOVANI e COSTA, 2018).

Apesar da grande importância da Mata Atlântica, uma extensa área de sua cobertura original foi substituída, remanescendo cerca de 7 a $8 \%$ das formações primárias (GALINDO-LEAL e CÂMARA, 2003). Ainda sobre o atual estado de conservação da MA, se consideradas formações florestais secundárias, resta algo próximo de $12 \%$ (SOS, 2008), sendo que alguns autores postulam até 27\% (IESB et al., 2007). Tamanha fragmentação florestal causa alterações significativas no solo e clima, além de colocar em risco de extinção diversas espécies que contribuem de forma significativa ao ambiente (MACHADO, 2003).

Dentre os vertebrados da Mata Atlântica, os anfíbios são os que apresentam maior declínio em abundância e riqueza (STUART et al., 2004). O Brasil é o país com a maior diversidade de anfíbios do planeta, com 1105 espécies conhecidas (SEGALLA et al., 2016; AMPHIBIAWEB, 2020). Devido a características físicas e fisiológicas, os anfíbios são sensíveis a alterações no habitat (TOLEDO et al., 2003). Deste modo, estudos de distribuição espacial e temporal das espécies são importantes, por demonstrar a extensão atual de ocorrência das espécies, contribuindo para o entendimento de como estão estruturadas tais comunidades (MOREIRA et al., 2008; SANTOS et al., 2008).

No estado do Paraná ocorrem 137 espécies de anfíbios anuros pertencentes a 13 famílias, destas, três espécies são listadas como ameaçadas nas listas vermelhas do Paraná, Brasil e / ou IUCN, sendo elas Brachycephalus pernix Pombal, Wistuba e Bornschein 1998, Dendropsophus anceps (Lutz, 1929) ambas classificadas como "Criticamente em Perigo" (CR) no Paraná e no Brasil, Limnomedusa macroglossa (Duméril e Bibron, 1841) classificada como "Criticamente em Perigo" (CR) no Paraná. As espécies Boana semiguttata (Lutz, 1925) e Ischnocnema paranaensis (Langone e Segalla, 1996) estão listadas como "Em Perigo" (EN) no Paraná e no Brasil (SANTOS-PEREIRA et al., 2018).

As espécies supracitadas correm risco de extinção por inúmeros impactos ambientais, dentre eles a inserção de barragens, isolamento/restrição das populações, pressão antrópica, introdução de espécies exóticas, o aumento da radiação ultravioleta, chuvas ácidas e poluição por conta de agrotóxicos (COLLINS e STORFER, 2003; KATS e FERRER, 2003; IAP, 2007, p. 214 - 218). 
Atualmente, ainda ocorrem muitas lacunas amostrais referentes às comunidades de anuros, já que ambientes mais preservados como as Unidades de Conservação (UCs) são pouco estudadas no que diz respeito à anurofauna (ICMBIO, 2012). Sobre as lacunas amostrais no estado do Paraná, “(...) a maioria dos estudos concentra-se ao redor de Curitiba, na região leste, provavelmente devido à presença de pesquisadores da Universidade Federal do Paraná, e do Museu de História Natural Capão da Imbuia. Em relação às demais regiões do estado, se nota um vazio amostral, com esporádicos estudos na região Norte, Oeste e Centro" (AFFONSO et al., 2015, p. 420).

Neste contexto, a porção do extremo Sul do Paraná ainda é pobremente inventariada. Estudos sobre a diversidade da anurofauna realizados próximos a região estão localizados no Estado vizinho, respectivamente em Lebon Régis, meio-oeste catarinense, com uma fitofisionomia de Floresta Ombrófila Mista (LINGNAU, 2009). Especificamente sobre o estado do Paraná, destaca-se aqui os estudos desenvolvidos em Morretes, localizada entre a serra e o litoral paranaense, com vegetação característica de Floresta Ombrófila Densa (ARMSTRONG e CONTE, 2010), São José dos Pinhais, localizada na porção leste do primeiro planalto paranaense, situado em um ecótono entre a Floresta Ombrófila Densa e a Floresta Ombrófila Mista (CONTE e ROSSA-FERES, 2006), Três Barras, localizada no terceiro planalto paranaense, com vegetação constituída pela Floresta Estacional Semidecídual (BERNARDE e MACHADO, 2001), Telêmaco Borba, localizada na região dos Campos Gerais no Estado do Paraná, com uma vegetação de Floresta Ombrófila Mista Montana, com forte influência da Floresta Estacional Semidecidual (MACHADO, 2004), Tijucas do Sul, localizada na porção sul do Primeiro Planalto Paranaense, com uma vegetação de Floresta Ombrófila Mista (CONTE e MACHADO, 2005) e Fazenda Rio Grande, sudeste paranaense, com uma vegetação de Floresta Ombrófila Mista (CONTE e ROSSA-FERES, 2007).

Portanto, o presente trabalho teve como objetivo realizar a descrição da estrutura da assembleia de anfíbios anuros terrestres da Floresta Estadual de Santana, região Sul do Estado do Paraná. Assim, tais dados são importantes por procederem de uma região onde ocorre uma lacuna amostral, visto que a maioria dos estudos concentra-se ao redor de Curitiba, onde encontram-se tradicionais centros de pesquisa em Zoologia. Além disso, estudos sobre a diversidade de anfíbios fornecem subsídios para pesquisas em diversas áreas da biologia, tais como a sistemática, ecologia e biogeografia, além do que, são fundamentais para a determinação de áreas prioritárias para a conservação, visto que os anfíbios anuros são um grupo taxonômico extremamente sensível a mudanças em seus habitats, pois apresentam baixa mobilidade, restrições fisiológicas devido a sua pele altamente permeável e a dependência tanto de ambientes aquáticos como terrestres em diferentes fases do ciclo de vida.

\section{MATERIAL E MÉtodos}

\section{1 Área de estudo}

A área de estudo trata-se da Floresta Estadual de Santana (26 04'28.29'S e $\left.50^{\circ} 45^{\prime} 48.43^{\prime \prime} \mathrm{O}\right)$, criada pelo decreto $\mathrm{n}^{\circ} .4 .264$ de 21.11.1994, perfazendo de uma área total de 60, 50ha (ATOS, 2019). Localmente, a UC é conhecida como Viveiro Florestal de Santana, localizado no município de Paulo Frontin, estado do Paraná, Brasil. A região possui um clima mesotérmico úmido, com média anual de temperatura de $17,2^{\circ} \mathrm{C}$ e precipitação média de $1.550 \mathrm{~mm} / \mathrm{ano}$ (CLIMA, 2019).

A vegetação é típica de Floresta Ombrófila Mista, caracterizada pela presença de pinheiros $A$. angustifolia (QUADROS e PILAR, 2002). Esta UC demonstra uma flora composta por pinheiros não maiores que $30 \mathrm{~cm}$ de diâmetro e diversos troncos caídos, 
demonstrando que há muito tempo a vegetação foi manejada, e hoje se apresenta em um estágio secundário de regeneração. A área possui habitats variados, com a presença de uma mata fechada, um riacho com uma profundidade média de $80 \mathrm{~cm}$ por dois metros de largura, bem como um lago ocasionado pelo represamento parcial do riacho local, com cerca de $147 \mathrm{~m}$ de comprimento por $47 \mathrm{~m}$ de largura e profundidade média de $60 \mathrm{~cm}$. Além disso, a UC é margeada pelo Rio Santana, de maior porte, com uma profundidade média de $80 \mathrm{~cm}$ por cerca de cinco metros de largura.

\subsection{Coleta de dados}

O inventário das espécies foi realizado por meio da captura de espécies, utilizando seis armadilhas de interceptação e queda (Figura 1a) do tipo Pitfall-trap ocorrendo a captura, marcação (Figura 1b). Foi realizada a aferição de peso e comprimento rostro-cloacal e posterior soltura dos espécimes próximo do local de coleta (CECHIN e MARTINS, 2000). Cada armadilha era composta por um recipiente de 200 litros com $85 \mathrm{~cm}$ de altura. Cada recipiente foi centralizado e interligado por três paredes de tela plástica, partindo de cada extremidade do pitfall formando um "Y", com cerca de $50 \mathrm{~cm}$ de altura e 6 metros de comprimento, totalizando cerca de $144 \mathrm{~m}^{2}$ de área amostral por armadilha, aproximadamente $864 \mathrm{~m}^{2}$ de área amostral total.

As armadilhas foram abertas em novembro de 2018 e permaneceram abertas até fevereiro de 2019, totalizando 33 amostragens de dois dias cada, cerca de nove por mês, totalizando 1.315 horas de armadilhas abertas. No interior das armadilhas foi mantido folhiço e galhos que ajudaram na manutenção de um microclima úmido, estimulando os indivíduos a se refugiarem entre a serapilheira dentro da armadilha. Assim, as armadilhas puderam ser revistadas a cada dois dias. A checagem das armadilhas ocorreu até às 10 horas da manhã, sendo somente contabilizados indivíduos capturados. Não foram coletados testemunhos e a identificação foi feita em campo com base em registros fotográficos e guias de identificação (KWET et al., 2010; BERNARDE, 2012; HADDAD et al., 2013).

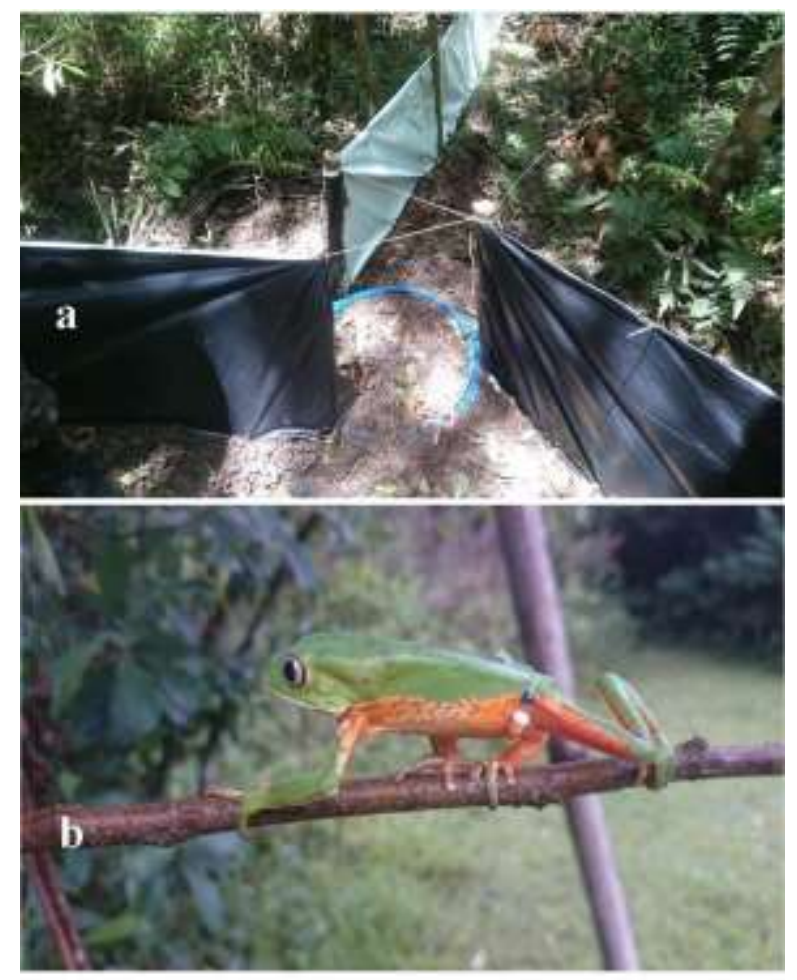

Figura 1: Imagem de uma armadilha de interceptação e queda e de um anfíbio marcado em campo (Pitfall-trap): (A) armadilha $\mathrm{n}^{\mathrm{o}}$. 4, (B) Phyllomedusa tetraploidea, visão lateral.

\subsection{Analise de dados}

As análises de biodiversidade foram aplicadas utilizando a matriz geral de capturas por amostragem. Essa matriz possibilitou a elaboração da curva de rarefação, por meio do índice de Mau-Tau, mais indicado para a construção de curvas-do-coletor com base em dados sem transformação. Tal curva do coletor foi utilizada para interpretar o esforço amostral necessário para atingir a riqueza esperada pelo índice de Chao2, já que houve espécies que ocorrem em apenas uma ou duas 
amostras, assim, este índice é indicado, pois baseia-se na incidência (BARROS, 2007). Os índices foram calculados por meio do software PAST (HAMMER et al., 2013). A abundância de cada espécie foi obtida por meio do número de capturas. A interpretação dos dados foi dada por meio de estatística frequentista de acordo com Gotelli e Ellison (2004).

\section{RESUltados}

Nesta pesquisa foram registradas 13 espécies, com uma riqueza esperada de 16sp (Chao 2), e um intervalo de confiança \pm 1 sp (Figuras 2 e 3). As espécies estão distribuídas nas famílias Bufonidae $(\mathrm{n}=2)$; Cycloramphidae $(n=1) ;$ Hylidae $(n=4)$; Leptodactylidae $(\mathrm{n}=4)$; Brachycephalidae $(n=1)$ e Microhylidae $(n=1$; Tabela, 1$)$.

Com relação à abundância das espécies foi observado um total de 361 capturas, não havendo nenhuma recaptura. Obteve-se média de 10,9 indivíduos por amostragem, aonde predominaram os gêneros Rhinella, Physalaemus e Leptodactylus, sendo estes responsáveis por $94,74 \%$ dos espécimes (Figura, 4).
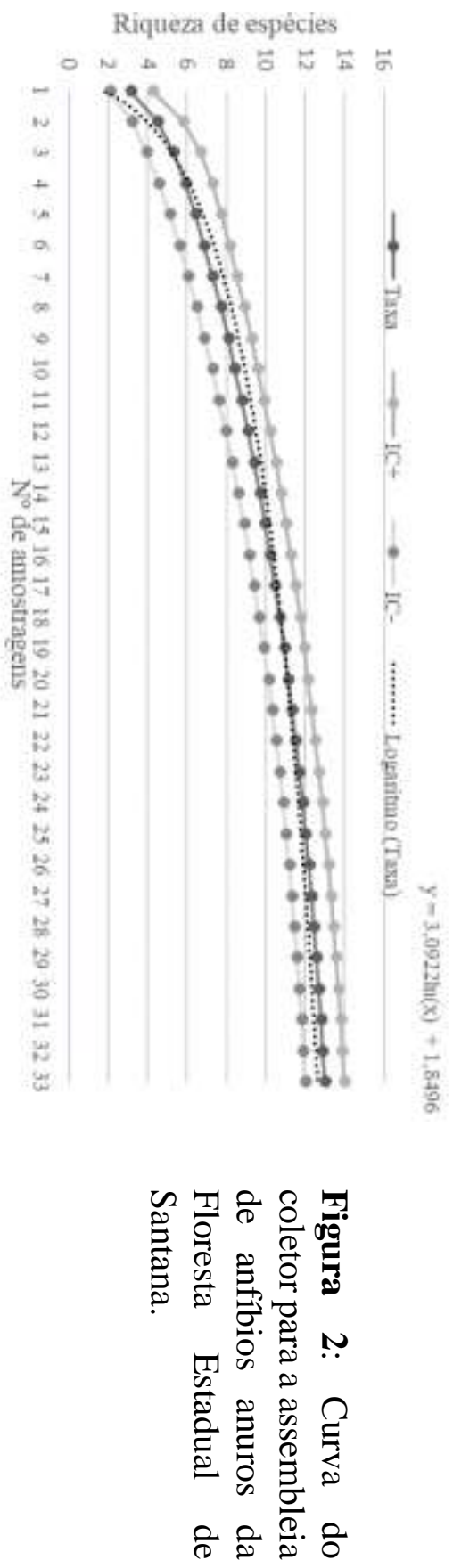


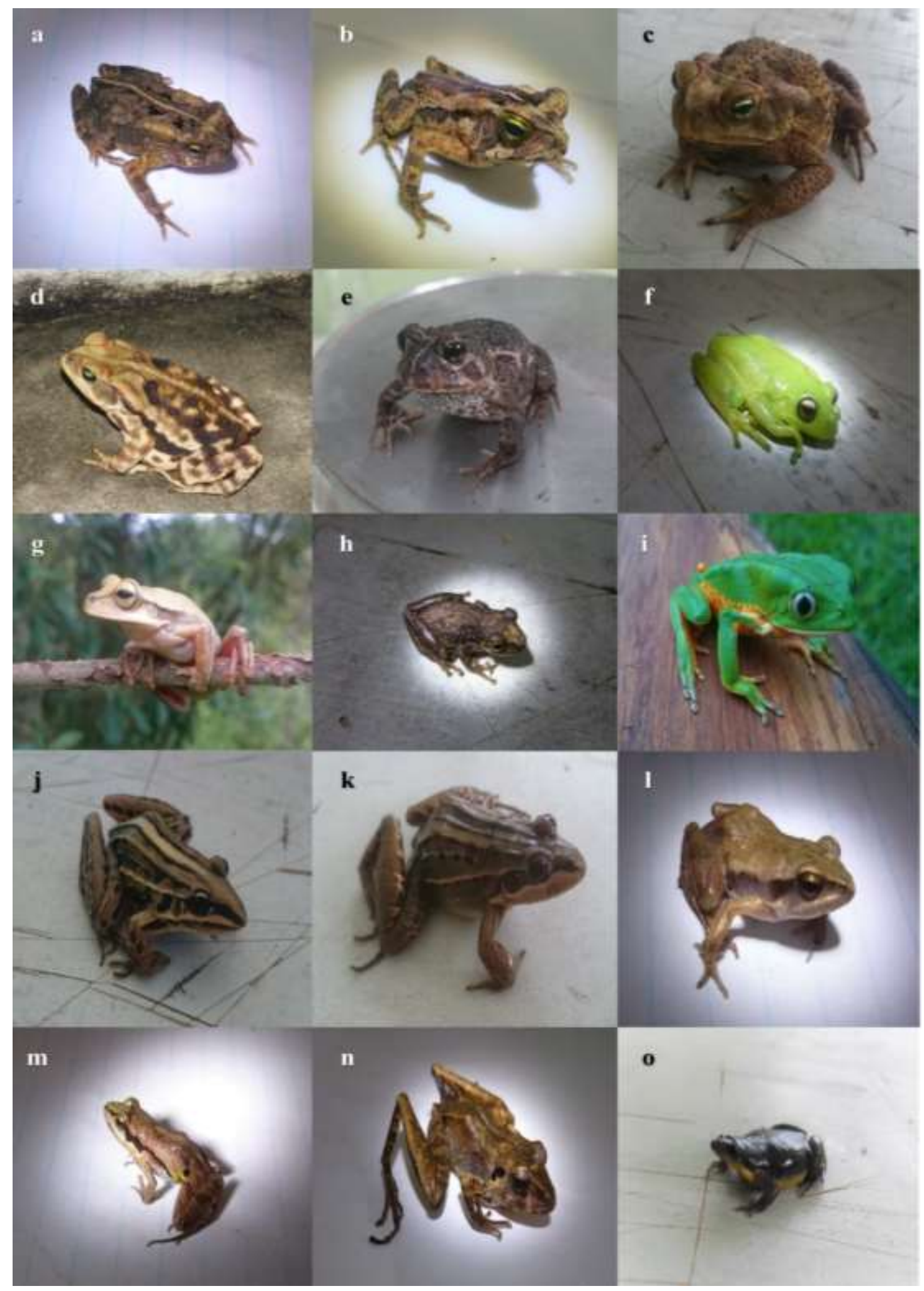

Figura 3: Imagens dos anfíbios capturados em campo, sendo eles: (A) Rhinella henseli (ठ), (B) Rhinella henseli (ㅇ), (C) Rhinella icterica (ठ̊), (D) Rhinella icterica (+), (E) Odontophrynus americanus, (F) Aplastodiscus perviridis, (G) Boana bischoffi, (H) Scinax perereca, (I) Phyllomedusa tetraploidea, (J) Leptodactylus gracilis, (K) Leptodactylus latrans, (L) Physalaemus cuvieri, (M) Physalaemus gracilis, (N) Ischnocnema henselii, (O) Elachistocleis bicolor. 


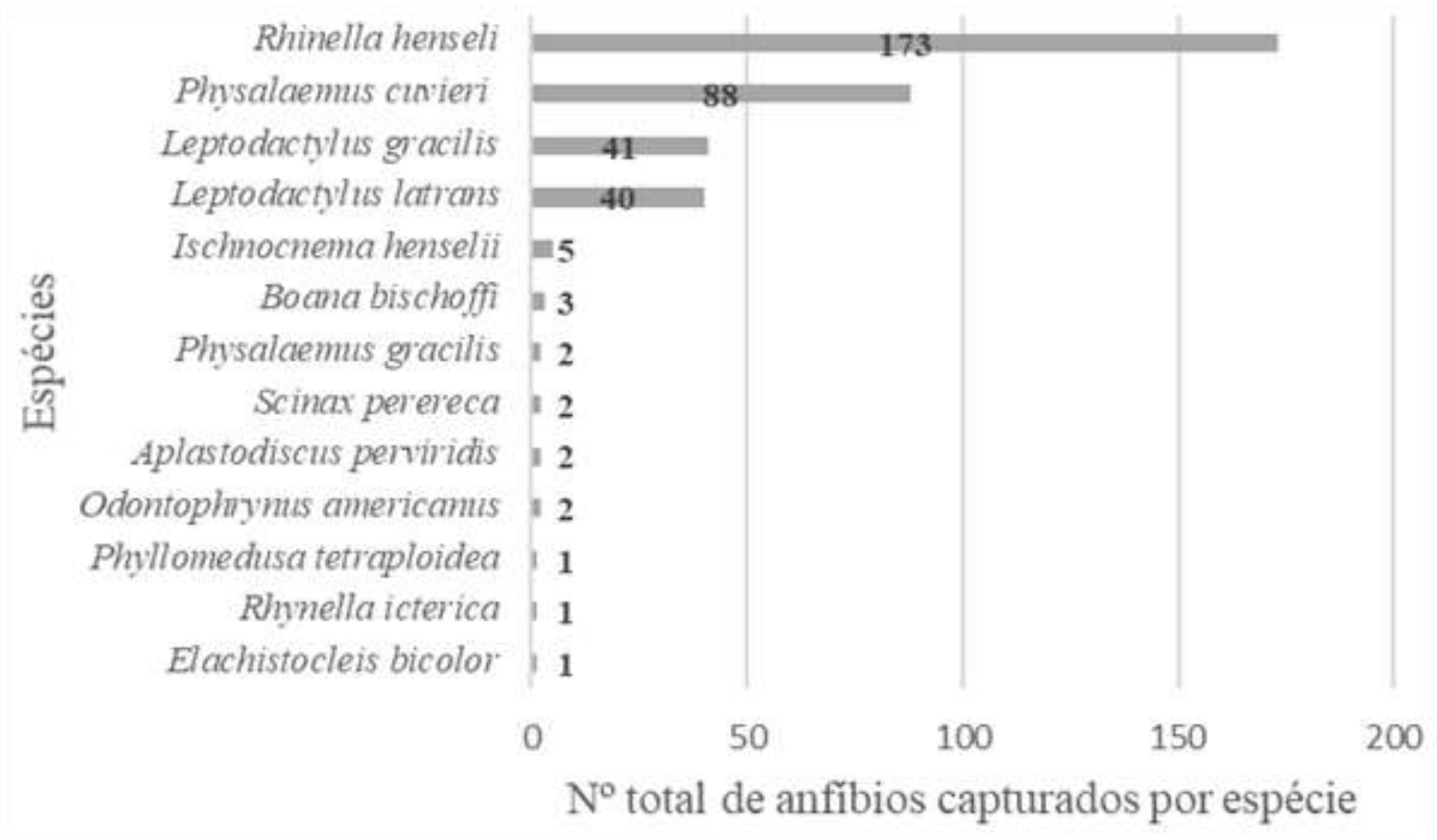

Figura 4: Número de anfíbios anuros capturados durante a pesquisa, demonstrando a abundância de cada espécie.

Tabela 1: Listagem das espécies de anfíbios encontradas na Floresta Estadual de Santana.

\begin{tabular}{|c|c|c|c|c|c|c|c|c|}
\hline \multirow{2}{*}{ FAMÍLIAS E ESPÉCIES } & \multirow{2}{*}{ NOME POPULAR } & \multicolumn{6}{|c|}{ PITFALL-TRAP (PT) } & \multirow{2}{*}{ TOTAL } \\
\hline & & PT 1 & PT 2 & PT 3 & PT 4 & PT 5 & PT 6 & \\
\hline \multicolumn{9}{|l|}{ BUFONIDAE } \\
\hline Rhinella henseli (Lutz, 1934) & Sapo (a) & 16 & 20 & 22 & 39 & 6 & 70 & 173 \\
\hline Rhinella icterica (Spix, 1824) & Sapo-cururu (b) & 0 & 1 & 0 & 0 & 0 & 0 & 1 \\
\hline \multicolumn{9}{|l|}{ CYCLORAMPHIDAE } \\
\hline Odontophrynus americanus (Dumeril \& Bibron, 1841) & Sapo-da-enchente (c) & 0 & 0 & 0 & 2 & 0 & 0 & 2 \\
\hline \multicolumn{9}{|l|}{ HYLIDAE } \\
\hline Aplastodiscus perviridis Lutz, 1950 & Perereca-verde (d) & 1 & 1 & 0 & 0 & 0 & 0 & 2 \\
\hline Boana bischoffi (Boulenger, 1887) & Perereca (e) & 1 & 2 & 0 & 0 & 0 & 0 & 3 \\
\hline Scinax perereca Pombal, Haddad \& Kasahara, 1995 & Perereca (f) & 0 & 1 & 1 & 0 & 0 & 0 & 2 \\
\hline Phyllomedusa tetraploidea (Pombal \& Haddad, 1992) & Perereca-verde $(\mathrm{g})$ & 0 & 1 & 0 & 0 & 0 & 0 & 1 \\
\hline \multicolumn{9}{|l|}{ LEPTODACTYLIDAE } \\
\hline Leptodactylus gracilis (Dumeril \& Bibron, 1841) & Rã-assoviadora (h) & 22 & 10 & 0 & 1 & 0 & 8 & 41 \\
\hline Leptodactylus latrans (Steffen, 1815) & Rã-manteiga (i) & 4 & 3 & 0 & 2 & 0 & 31 & 40 \\
\hline Physalaemus cuvieri Fitzinger, 1826 & Rã-cachorro (j) & 5 & 18 & 14 & 6 & 0 & 45 & 88 \\
\hline Physalaemus gracilis (Boulenger, 1883) & Rã-chorona (k) & 0 & 0 & 0 & 0 & 2 & 0 & 2 \\
\hline \multicolumn{9}{|l|}{ BRACHYCEPHALIDAE } \\
\hline Ischnocnema henselii (Peters, 1870) & Rã-do-folhiço (l) & 0 & 0 & 2 & 3 & 0 & 0 & 5 \\
\hline \multicolumn{9}{|l|}{ MICROHYLIDAE } \\
\hline Elachistocleis bicolor (Guérin-Méneville, 1838) & Rãzinha (m) & 0 & 0 & 1 & 0 & 0 & 0 & 1 \\
\hline TOTAL & & 49 & 57 & 40 & 53 & 8 & 154 & 361 \\
\hline
\end{tabular}




\section{DisCUSS̃̃o}

A riqueza encontrada de 13 espécies pode ser considerada baixa quando comparada àquela de pesquisas realizadas em áreas próximas. Por exemplo, em uma área constituída de Floresta Estacional Semidecidual foram encontradas 54 espécies (MACHADO, 2004), enquanto em áreas de Floresta Ombrófila Densa (ARMSTRONG e CONTE, 2010) e Floresta Ombrófila Mista (CONTE e ROSSA-FERES, 2007; LINGNAU, 2009) obtiveram uma riqueza de 32 espécies em cada respectivamente. Em outras duas áreas constituídas de Floresta Estacional Semidecidual (BERNARDE e MACHADO, 2001) e Floresta Ombrófila Mista (CONTE e MACHADO, 2005) obtiveram uma riqueza de 23 espécies concomitantemente.

A diferença entre o número de capturas pode ser explicada pelo uso de diferentes metodologias, sendo que Machado (2004) utilizou a metodologia de transecção onde as espécies que estavam vocalizando foram registradas, enquanto Bernarde e Machado (2001) utilizaram a metodologia de busca auditiva e visual em períodos diurnos e noturnos. Conte e Machado (2005) amostraram espécies em atividade de vocalização, bem como seus sítios de vocalização, Armstrong e Conte (2010) utilizaram duas metodologias, sendo estas, (1) levantamento em sítio de reprodução e (2) transecção por busca aural, efetuado em um trecho de $200 \mathrm{~m}$ no interior da floresta, Lingnau (2009) utilizou três metodologias diferentes, sendo estas: (1) levantamento em sítio reprodutivo, (2) busca ativa e (3) transecção por busca aural, e Conte e RossaFeres (2007) utilizaram quatro metodologias, sendo (1) inventariamento em sítio reprodutivo, (2) transecção por busca aural, (3) busca ativa e (4) amostragens de girinos.

Em relação à predominância das famílias, Hylidae e Leptodactylidae foram as mais representativas, resultado também observado nos estudos de Bernarde e Machado (2001), Conte e Machado (2005),
Conte e Rossa-Feres (2006), Lingnau (2009), Armstrong e Conte (2010), já para Conte e Rossa-Feres as famílias predominantes foram Hylidae e Cicloramphidae isso porque de acordo com Peres (2010) e Pereira-Junior et al. (2013) a predominância dessas família é comum em estudo realizados em regiões neotropicais.

Já em relação à predominância dos gêneros Rhinella, Physalaemus e Leptodactylus, foram os mais observados nesta pesquisa, resultado também observado no estudo de Conte e Rossa-Feres (2006) outros estudos próximos não obtiveram estes resultados. Armstrong e Conte (2010) obtiveram como gêneros predominantes Scinax e Dendropsophus, Lingnau (2009) obteve como predominante os gêneros Boana, Scinax e Leptodactylus enquanto Conte e Rossa-Feres (2007) obtiveram os gêneros predominantes Scinax, Boana, Leptodactylus e Dendropsophus. Mesmo apresentando resultados distintos, nenhum dos estudos relatados deixou de citar gêneros como Dendropsophus, Leptodactylus e Physalaemus, sendo estes gêneros sempre reportados por apresentarem plasticidade adaptativa, podendo colonizar desde áreas de extensa cobertura vegetal, até áreas com grandes alterações de sua paisagem natural (TOLEDO, 2009).

As espécies mais abundantes foram Rhinella henseli (173 capturas), Physalaemus cuvieri (88 capturas) e Leptodactylus gracilis (41 capturas). Esse padrão difere daquele observado em áreas próximas. Por exemplo, o estudo de Conte e Rossa-Feres (2007) obteve Boana Bischoffi (84 indivíduos), Dendropsophus minutus (79 indivíduos) e Scinax perereca (61 indivíduos) como espécies de maior abundância. Contudo, é importante ressaltar que a maior parte dos estudos utilizam metodologias mistas, enquanto este foca apenas no método passivo.

A presença de algumas espécies pode dizer muito sobre a situação do local. E.g. Physalaemus cuvieri, Leptodactylus latrans são consideradas indicadoras de ambientes 
abertos ou com baixa qualidade ambiental (TOLEDO, 2009; VASCONCELOS et al., 2010). Por outro lado, a presença de espécies mais sensíveis as alterações ambientais, como Ischnocnema henselii geralmente de ocorrência restrita aos ambientes florestais é considerada indicadora de ambientes com boa qualidade (KWET et al., 2010), indicando um avanço da regeneração natural do local, ressaltando a necessidade de esforços para melhorar a qualidade da UC frente a finalidade conservacionista.

\subsection{Conclusão}

Os dados apresentados demonstram que a estrutura da assembleia de anfíbios anuros é compatível com a de ambientes de baixa qualidade, já que apresenta grande ocorrência de indivíduos do gênero Physalaemus e Leptodactylus, espécies comumente encontradas em ambientes antropizados. A espécie considerada indicadora de ambientes com boa qualidade Ischnocnema henselii - apresentou baixa abundância.

Sugere-se que a elaboração do plano de manejo leve em conta estratégias para contribuir com permanência e conservação da anurofauna local, já que estes indivíduos são extremamente vulneráveis a alterações no ambiente. Recomenda-se em termos conservacionistas, que se aumente a intensidade de proteção da matriz florestal para aquelas espécies estritamente florestais, bem como a preservação da vegetação próxima dos cursos hídricos.

\section{Agradecimentos}

Ao Sr. Aramis Konart e todos os membros do Instituto Ambiental do Paraná pelo apoio logístico. À Sra. Maria de Lurdes Wacholsbielik por toda ajuda e hospitalidade cedida durante a fase de campo. Agradecemos também aos biólogos Emerson Ricardo dos Santos e Nycolle Machado da Rosa por toda a ajuda durante a pesquisa. $\mathrm{O}$ autor $\mathrm{EB}$ agradece e dedica este estudo à Norberto Antonio Biella, Cristina Lasch Biella, Matheus Biella e Pedro Ricardo Biella. O autor agradece especialmente à Evelin Suzana L. de Souza pelas longas horas de trabalho conjunto em campo. Finalmente, somos gratos ao Instituto Chico Mendes de Conservação da Biodiversidade pela autorização para atividade cientifica $\mathrm{N}^{\mathrm{o}}$ 66613-1.

\section{REFERÊNCIAS}

AFFONSO IP, BATISTA VG, ODA FH, GAMBALE PG, GOMEZ LC, BASTOS RP. Publicações científicas em Herpetologia na região Sul do Brasil. Boletim do Museu de Biologia Mello Leitão, Maringá, v. 4, n. 37 p. 409-425, 2015.

AMPHIBIAWEB. Disponível em: $<$ https://amphibiaweb.org/cgi/amphibquery?r el-common-ordr=any\&relisocc $=$ occurs + in $\&$ where-isocc $=$ Brazil $\&$ relspecies>. Acesso 13 abril 2020.

ARMSTRONG CG, CONTE CE. Taxocenose de anuros (Amphibia: Anura) em uma área de Floresta Ombrófila Densa no Sul do Brasil. Revista Biota Neotropica, São Paulo, v. 10, n. 1, p. $39-46,2010$.

ATLAS DOS REMANESCENTES FLORESTAIS DA MATA ATLÂNTICA PERÍODO 2016-2017. Área de Aplicação da Lei 11.428 de 2006, a Lei da Mata Atlântica. SOS Mata Atlântica e o Instituto Nacional de Pesquisas Espaciais, 2016 - 2017.

ATOS DE CRIAÇÃO DE UNIDADES DE
CONSERVAÇÃO. Disponível em: 
<http://www.iap.pr.gov.br/pagina1217.html>. Acesso em: 21 junho 2019.

BARROS RSM. MEDIDAS DE DIVERSIDADE BIOLÓGICA. 2006. 16 p. Pós-Graduação (Ecologia) -Universidade Federal de Juiz de Fora, Juiz de Fora, 2007.

BERNARDE PS. Anfíbios e Répteis: Introdução ao Estudo da Herpetofauna Brasileira. Curitiba: Anolis books, 2012, 320 p.

BERNARDE PS, MACHADO RA. Riqueza de espécies, ambientes de reprodução e temporada de vocalização da anurofauna em Três barras do Paraná, Brasil (Amphibia: Anura). Cuadernos de herpetologia, Três Barras, v. 14, n. 2, p. 93 - 104, 2001.

CECHIN SZ, MARTINS M. Eficiência de armadilhas de queda (pitfalltraps) em amostragens de anfíbios e répteis no Brasil. Revista Brasileira Zoologia, São Paulo, v. 17, n. 3, p. 729- 740, 2000.

CLIMA PAULO FRONTIN. Disponível em: $<$ https://pt.climate-data.org/america-dosul/brasil/parana/paulo-frontin-57371/>. Acesso em: 21 junho 2019.

COLLINS JP, STORFER A. Global amphibian embryos and larvae. Canadian Journal of Zoology, v. 63, p. 116 - 123, 2003.

CONTE CE, MACHADO RA. Riqueza de espécies e distribuição espacial e temporal em comunidades de anuros (Amphibia, Anura) em uma localidade de Tijucas do Sul, Paraná,
Brasil. Revista Brasileira de Zoologia, Curitiba, v. 22, n. 4, p. 940 - 948, 2005.

CONTE CE, ROSSA-FERES DC. Diversidade e ocorrência temporal da anurofauna (Amphibia, Anura) em São José dos Pinhais, Paraná, Brasil. Revista Brasileira de Zoologia, São José dos Pinhais, v. 23, n. 1, p. $162-175,2006$.

CONTE CE, ROSSA-FERES DC. Riqueza e distribuição espaço-temporal de anuros em um remanescente de Floresta de Araucária no sudeste do Paraná. Revista Brasileira de Zoologia, São José do Rio Preto, v. 24, n. 4, p. $1025-1037,2007$.

COSTA HC, BÉRNILS RS. Répteis brasileiros: Lista de espécies 2015. Herpetologia Brasileira, Belo Horizonte, v. 4, n. 3, p. 75-93, 2015.

GALINDO-LEAL C, CÂMARA IG. Atlantic Forest hotspot status: an overview. In: Galindo-Leal, C., Câmara, IG (Eds.), The Atlantic Forest of South America: Biodiversity Status, Threats and Outlook. CABS and Island Press, Washington, p. 311, 2003.

GOTELLI NJ, ELLISON AMA. A Primer of Ecological Statistics. Sunderland, MA: Sinauer Associates, 2004.

HADDAD CFB. Livro Vermelho da Fauna Brasileira Ameaçada de Extinção: Volume V. São Paulo: ICMBio/MMA, 2018, 286 $324 \mathrm{p}$. 
HADDAD CFB, TOLEDO LF, PRADO CPA, LOEBMANN D, GASPARINI JL, SAZIMA I. Guia dos Anfíbios da Mata Atlântica - Diversidade e Biologia. São Paulo: Anolis Books, 2013, 543 p.

HICKMAN CP, ROBERTS LS, KEEN SL, EISEN HOUR DJ, LARSON A, I'ANSON H. Princípios integrados de Zoologia. Rio de Janeiro: Guanabara Kogan, 2016, 1405 p.

HAMMER $\varnothing$, HARPER DAT, RYAN PD. Past: Paleontological Statistics Software Package for Education and Data Analysis. Palaeontologia Electronica, v. 4, p. 9, 2001.

IAP. Instituto Ambiental do Paraná. Fauna do Paraná em extinção, Curitiba, 2007.

ICMBIO. Instituto Chico Mendes, SUMÁRIO EXECUTIVO DO PLANO DE AÇÃO NACIONAL PARA A CONSERVAÇÃO DOS ANFÍBIOS E RÉPTEIS AMEAÇADOS DA REGIÃO SUL DO BRASIL, Brasília, 2012.

INSTITUTO DE ESTUDOS SÓCIO AMBIENTAIS DO SUL DA BAHIA (IESB), INSTITUTO DE GEOCIÊNCIAS DA UNIVERSIDADE FEDERAL DO RIO DE JANEIRO (IGEO/UFRJ), DEPARTAMENTO DE GEOGRAFIA DA UNIVERSIDADE FEDERAL FLUMINENCE (UFF). Levantamento da Cobertura Vegetal Nativa do Bioma Mata Atlântica. Relatório final. PROBIO 03/2004, Brasília, p. 84, 2007.

KATS LB, FERRER RP. Alien predator and amphibian declines: rewiew of two décadas of Science and transition to conservation.
Diversityand Distributions, v. 9, n. 2, 9. 99 $-110,2003$.

KWET A, LINGNAU R, DI-BERNARDO M. Anfíbios - Amphibien - Amphibians: Serra Gaúcha. Porto Alegre: EDIPUCRS, 2010, $148 \mathrm{p}$.

LINGNAU R. Distribuição temporal, atividade reprodutiva e vocalizações em uma assembleia de anfíbios anuros de uma Floresta Ombrófila Mista em Santa Catarina, Sul do Brasil. 2005, 103.Tese (Doutorado em Zoologia) - Pontifícia Universidade Católica do Rio Grande do Sul, Porto Alegre, 2009.

MACHADO MABL. Florística e fitossociologia do estrato arbóreo de fragmentos de mata atlântica da usina Coruripe - estado de Alagoas. 2002, 100 p. Dissertação (Mestrado em Agronomia) Universidade Federal de Alagoas, Rio Largo, 2003.

MACHADO R. A. Ecologia de assembléias de anfíbios anuros no município de Telêmaco Borba, Paraná, Sul do Brasil. 2004, 128. Monografia (Graduação) Universidade Federal do Paraná, Curitiba, 2004.

MINISTÉRIO DO MEIO AMBIENTE: MATA ATLÂNTICA. Disponível em: $<$ https://www.mma.gov.br/biomas/mataatl\%C3\%A2nticaemdesenvolvimento.html>. Acesso em: 16 março 2020.

MANTOVANI A, COSTA NCFD. Situação atual e conservação das Florestas com Araucária. In: Seminário Sul-Brasileiro sobre 
a Sustentabilidade aa Araucária, 3, 2018, Passo Fundo - RS. Palestra. Local: Passo Fundo: Livraria e EditoraWerlang LTDA, 2018. P. 268.

MOREIRA LFB, MACHADO IF, LACE ARGM, MALTCHIK L. Anuran amphibians dynamics in an intermittent pond in southern Brazil. Acta Limnol, Brasília, vol. 20, n. 3, p. 205-212, 2008.

NODARI ES, CARVALHO MMX, MORETTO SP. A Conservação do Oeste Catarinense: Parque Nacional das Araucárias e a Estação Ecológica da Mata Preta. $1^{\text {a }}$ Edição, Rio do Sul, 2009, 75 p.

PERES P. Taxocenose de anfíbios anuros do parque ecoturistico e ecológico de Pedras Grandes, SC. 2010, 86 p. Monografia (Graduação) - Universidade do Extremo Sul Catarinense/UNESC, Criciúma, 2010.

PEREIRA-JUNIOR AP, COSTA-CAMPOS CE, ARAUJO AS. Composição e diversidade de anfibios anuros do campus da Universidade Federal do Amapá. Biota Amazônia, Macapá, v. 3, n. 1, p. 13-21, 2013.

QUADROS FLF, PILLAR VD. Transições floresta-campo no Rio Grande do Sul. Ciência \& Ambiente, Santa Maria, v. 24, n. 13, p. 109-118, 2002.

SANTOS-PEREIRA M, JUNIOR JPP, ROCHA CFD. Anuran amphibians in state of Paraná, southern Brazil. Revista Biota Neotropica, Rio de janeiro, v. 18, n. 3, p. 01 $-19,2018$.
SANTOS TG, KOPP K, SPIES MR, TREVISAN R, CECHIN SZ. Distribuição temporal e espacial de anuros em área de Pampa, Santa Maria, RS. Biblioteca Digital da Produção Intelectual - BDPI, Santa Maria, v. 98, n. 2, p. 244-253, 2008.

SEGALLAMV, CARAMASCHI U, CRUZ CAG, GRANT T, HADDAD CFB, LANGONE JA, GARCIA PCDA, BERNECK BVM, POMBAL JJ. Brazilian Amphibians: List of Species. Herpetologia Brasileira, São Paulo, v. 5, n. 2, p. 34-46, 2016.

SOS MATA ATLÂNTICA, INSTITUTO NACIONAL DE PESQUISAS ESPACIAIS, 2008. Atlas dos remanescentes florestais da Mata Atlântica, período de 2000 a 2005. Disponível em: <https://www.sosma.org.br/>. Acesso em: 15 março 2020.

STUART S, CHANSON JS, COX NA, YOUNG BE, RODRIGUES ASL, FISCHMAN DL, WALLER RW. Status and trends of amphibian declines and extinctions worldwide. Science, v. 3, n. 2, p. 197 - 212, 2004.

TOLEDO LF. Anfíbios como bioindicadores. In: Bioindicadores da qualidade ambiental (S. Neumann-Leitão e S. El-Dier, org.). Instituto Brasileiro Pró-Cidadania, Recife, p.196208, 2009.

TOLEDO LF, CARVALHO-E-SILVA SP, SÁNCHEZ C, ALMEIDA MA, HADDAD CFB. The review of the Brazilian Forst Act: harmful effects on amphibian conservation. Biota Neotropica, Campinas, v. 10, n. 4, p. 35-38, 2010. 
TOLEDO LF, ZINA J, HADDAD CFB.

Temporal and Spatial Distribution in an Anuran Community in Municipality of Rio Claro, São Paulo, Brazil. Holos Environ, São Paulo, v. 3, n. 2, p. 136-149, 2003.

VASCONCELOS TS, ROSSA-FERES DC. Diversidade, distribuição espacial e temporal de anfíbios anuros (Amphibia, Anura) na região noroeste do estado de São Paulo, Brasil. Biota Neotropica, Campinas, v. 5, n. 2, 2005.

VASCONCELOS TS, SANTOS TG, ROSSA-FERES DC, HADDAD CFB. Similarity of ground-dwelling anuran (Amphibia) composition among different vegetation physiognomies in a Mesophytic Semideciduous Forest from southeastern Brazil. North-western Journal of Zoology, v. 6, n. 2, p. 275-285, 2010.

Submetido: 17/12/2019.

Aceito: 21/05/2020. 